\title{
Cutaneous Manifestations of Chronic Kidney Disease-An Observational Study in 100 Cases
}

\author{
JA Leena ${ }^{1}$, MU Noman ${ }^{2}$, MMSU Islam³ ${ }^{3}$ AS Ahmed ${ }^{4}$, DS Ahmed ${ }^{5}$, MM Rahman $^{6}$
}

\begin{abstract}
Chronic Kidney Disease (CKD) presents with an array of cutaneous manifestations. Newer changes are being described since the advent of haemodialysis, which prolongs the life expectancy, giving time for these changes to manifest. This cross sectional study was performed in 100 cases of CKD admitted in nephrology department of Dhaka Medical College Hospital (DMCH) and Bangabandhu Sheikh Mujib Medical University (BSMMU) from April 2008 to August 2008 to evaluate the prevalence of dermatologic problems. Among them most belong to 2nd to 5 th decade, 68 are male and rests are female. Glomerulonephritis (44\%), Diabetes mellitus (22\%), Obstructive uropathy (13\%) and Hypertensive nephropathy (12\%) are found common causes of CKD. Among these patients $38 \%$ patients were treated with conservative treatment, $31 \%$ with intermittent peritoneal dialysis (IPD), $19 \%$ with haemodialysis and $12 \%$ with some form of immunosuppressive therapy. Total $88 \%$ of study population had some form of skin disorder; pallor was the most common (82\%), while xerosis (61\%), pruritus (53\%), pigmentation (37\%) and bacterial infection (37\%) were other common problems. Purpura and fungal infection was $29 \%$ and $27 \%$ respectively. Viral infection (9\%), dermatitis (4\%), gynaecomastia (1\%), kyrle's disease (3\%) are relatively less common findings. Lindsay's nail was seen in $23 \%$ of patients and was more prevalent in glomerulonephritis and diabetic patients with prevalence of $13 \%$ and $9 \%$ respectively. Other nail changes included koilonychia (4\%), subungual hyperkeratosis (1\%), splinter hemorrhages $(3 \%)$ onychomycosis $(8 \%)$ and Beau's lines $(1 \%)$. So, CKD is associated with a complex array of cutaneous manifestations caused either by the disease or by treatment.
\end{abstract}

Key words: Chronic Kidney Disease, Cutaneous Manifestations.

\section{Introduction :}

The skin is the largest body organ that shows remarkable functional and structural diversity ${ }^{1-4}$. CKD defined as evidence of kidney damage over 3 months period with or without reduction of glomerular filtration rate revealed by clinical assessment, abnormal urinary finding, abnormal renal imaging, genetic disease or histologically proven disease ${ }^{5}$. CKD is associated with array of skin problems. In the past most frequent

1. Dr. Jesmin Akhter Leena, FCPS (Dermatology), Medical Officer, GOD, Shere Bangla Nagar, Dhaka.

2. Dr. Mesbah Uddin Noman, FCPS (Medicine), MD Nephrology 3rd part student, Dept. of Nephrology, DMCH, Dhaka.

3. Dr. M.M. Shahin-U1-Islam, FCPS (Medicine), MD (Gastroenterology), Asst. Professor, Dept. of Gastroenterology, FMC, Faridpur.

4. Dr. Abu Saleh Ahmed, FCPS (Medicine), MD Nephrology 3rd part student Dept. of Nephrology, DMCH, Dhaka.

5. Dr. Dewan Saifuddin Ahmed, FCPS (Medicine), MD (Gastroenterology), Associate Professor, Dept. of Gastroenterology, BSMMU, Dhaka.

6. Prof. M. Muhibur Rahman, FCPS, MRCP, PhD (Nephrology), Professor of Nephrolgy, NIKDU, Dhaka.

Address of correspondence

Dr. Jesmin Akhter Leena, FCPS (Dermatology), Medical Officer, GOD, Shere Bangla Nagar, Dhaka. Phone: 088-0171-3386262, Email: dr_munoman@yahoo.com. problems were 'uraemic frost' and 'erythema papulatum uremicum'. Uraemic roseola and uraemic erysepeloid were also seen in patients with advanced renal failure. More recently with advent of dialysis these skin lesions have become rare, but several other abnormalities of skin and the appendages have emerged like fibrosing nephrogenic dermopathy which may be associated with calciphylaxis and metastatic calcification ${ }^{6}$.

Xerosis was the most common cutaneous abnormality observed in previous reports $(46-90 \%)^{7-9}$. A reduction in the size of eccrine sweat glands may be contributory, although high dose diuretic regimens are also implicated $^{10,11}$. Pruritus is one of the most characteristic and annoying cutaneous symptoms of $\mathrm{CKD}^{10-13}$. The etiology of pruritus in CKD is unknown. However, it has been associated to renal insufficiency, secondary hyperparathyroidism, xerosis, increased serum levels of magnesium, calcium, phosphate, aluminum, histamine, proliferation of nonspecific enolase-positive sensory nerves in the skin, hypervitaminoses $\mathrm{A}$ and iron deficiency anemia ${ }^{14-16}$. Pallor of the skin due to anemia reported as the hallmark of CKD. Two types of pigmentary changes were observed: hyperpigmentation, attributed to an increase in melanin in the basal layer and superficial dermis due to failure of the kidneys to excrete beta-melanocyte-stimulating hormone (b-MSH) 
and a yellowish tinge attributed to the accumulation of carotenoids and nitrogenous pigments. Perforating disorders such as perforating folliculitis, Kyrle's disease and reactive perforating collagenosis have been described in $\mathrm{CKD}^{17}$. Metastatic calcification of the skin in CKD results from secondary or tertiary hyperparathyroidism ${ }^{18}$. These dermatological diseases in most cases are not part of irreversible stigmata of CKD, rather they demand appropriate attention, proper diagnosis and in most cases treatment can be provided with symptomatic relieve of the patient. This study was done to find out the prevalence and pattern of dermatological disorders in chronic kidney disease patients.

\section{Materials and Methods:}

This observational study was carried out at Nephrology department of DMCH \& BSMMU from April 2008 to August 2008. Total $100 \mathrm{CKD}$ patients diagnosed on the basis of estimated GFR by Cockroft-Gault formula, persistent urinary abnormality or abnormal renal imaging for a period of 3 months were selected by continuous purposive sampling. Patients with coexistent malignancy were excluded from the study. Detailed history and thorough physical examination was done in each patient to find out different arrays of skin manifestations. Findings were then calculated keeping the view of the study and presented accordingly.

\section{Results:}

Among 100 patients highest number belongs to 3rd decade $(24 \%)$, followed by 2 nd decade $(19 \%)$ and 4 th decade $(18 \%)$. Age ranged from 8 to 76 years; 68 were male and 32 were female.

Regarding etiology of CKD, glomerulonephritis (44\%) is the leading cause followed by diabetes mellitus $(22 \%)$, obstructive nephropathy (13\%), and hypertensive nephropathy (12\%). Male predominance was observed in all etiological groups except in SLE, on the other hand CKD due to obstructive nephropathy was found to be rare among female. A few cases with relatively uncommon etiology like Alport's syndrome (1\%), Autosomal Dominant Polycystic Kidney Disease (3\%) was included.

Treatment modalities for CKD patient varies from conservative therapy to renal transplantation. In this study $31 \%$ patients are being treated with IPD which is only superseded by conservative treatment (38\%). Only $19 \%$ patients are receiving haemodialysis and none with renal transplant. However $12 \%$ patients are receiving immunosuppressive agent like cyclophosphamide, chlorumbucil with steroids as treatment for active glomerulonephritis.

Among study population $88 \%$ had some form cutaneous complain while, only $18 \%$ were free from any skin disorders. Pallor was found to be most common skin manifestation among CKD patient $(82 \%)$, while xerosis (61\%), pruritus (53\%), pigmentation (37\%) and bacterial (37\%) infection were other common problems. Prevalence of purpura and fungal infection was $29 \%$ and $27 \%$ respectively. Viral infection (9\%), dermatitis (4\%), gynaecomastia (1\%), kyrle's disease (3\%) are relatively less common findings.

\section{Discussion:}

Cutaneous manifestations are very common in patients with chronic kidney disease. Pico et $\mathrm{al}^{10}$ and Bencini et $\mathrm{al}^{14}$ found prevalence of kidney disease in $100 \%$ and $79 \%$ patients respectively. Udayakumar et $\mathrm{al}^{19}$ has performed a study among patients receiving haemodialysis and cutaneous disorders were found in $82 \%$ patients. Among study population $88 \%$ had some form cutaneous complain while, only $18 \%$ was free from all skin disorder. These findings of the study accords with previous study.

Pallor $(82 \%)$ was found to be most common skin manifestation among CKD patients in this study. Study done by Udayakumar et al ${ }^{19}$ pallor was observed in only $60 \%$ of patients, possibly because of the darker complexion. The hemoglobin level was less than $8 \mathrm{~g} \mathrm{\%}$ in $64 \%$ of the patients. This is a common early finding and adds significantly to the mortality. ${ }^{11}$ Pallor was found to be more prevalent in comparison to previous study, one possibility for this difference is that in second mentioned study population was the patients on maintenance hemodialysis, who usually receive regular blood transfusion, on the contrary in this study population patients belonging to different stages of CKD at hospital admission were included who may not yet got any attention towards treatment of anemia. Xerosis $(61 \%)$ was the second most common presentation, while xerosis was the most common cutaneous abnormality $(79 \%)$ in study done by Udayakumar et $\mathrm{al}^{19}$. Prevalence of xerosis observed in previous reports $(46-90 \%)^{7-9}$. In Udayakumar et al ${ }^{19}$ study, $53 \%$ of patients complained of pruritus. Fifteen (28\%) patients had pruritus before the diagnosis of CRF. Thirty eight out of 53 patients $(72 \%)$ found no improvement following dialysis, $5(9.4 \%)$ showed improvement and 10 patients $(18.8 \%)$ reported aggravation after hemodialysis. It was found to be severe in diabetic patients. ${ }^{7}$ In this present study pruritus was found in same proportion 53\%. Though the previous mentioned study has look into relation between dialysis and pruritus, such correlation was not investigated in the present study due to short duration of 
study. Pigmentation (37\%) was next common skin disorder found among patients of CKD. In the study done by Udayakumar et $\mathrm{al}^{19}$ two types of pigmentary charges were observed: hyperpigmentation (seen in $43 \%$ of patients) and a yellowish tinge to the skin $(10 \%)$ with prominent hyperpigmentation over the sunexposed areas was seen in $26 \%$. Other authors have reported a prevalence of $20-22 \%{ }^{7,10}$. Udayakumar et $\mathrm{al}^{19}$ found sixty-seven skin infections (13 bacterial, 42 fungal and 12 viral), distributed amongst 40 patients. Bacterial infections seen in 13 patients, were common in diabetics. The fungal infections were distributed among 30 patients $(30 \%)$. Pityriasis versicolor was seen in 15 patients $(15 \%)$. The viral infections included warts $(8 \%)$, herpes simplex $(3 \%)$ and herpes zoster $(1 \%)$. Bencini et al have reported the incidence of fungal infection in patients undergoing hemodialysis to be $67 \%{ }^{14}$. Tinea pedis, also reported to be common ${ }^{10}$. In the present study bacterial infection, fungal infection and viral infection were found in $37 \%, 27 \%$ and $9 \%$ respectively. However pattern of fungal infection accords with that found in previous study. One possible explanation for increased bacterial infection found in this study is 19 patients were found to have thrombophlebitis secondary to cannulation. Pattern of infection may also vary with type of immunosuppression that occurs in different group of patients treated with different modalities of treatment.

APD has been reported to occur in $4.5-17 \%$ of patients on hemodialysis ${ }^{8,10}$. Udayakumar et $\mathrm{al}^{19}$ encountered Kyrle's disease in 21 patients (21\%); 19 of them had undergone dialysis for less than 6 months. These changes were significantly more prevalent in diabetic patients. In the present study kyrle's disease is found in only $3 \%$ cases. This difference with the study done by Udayakumar et $\mathrm{al}^{19}$ is significant and the reason may be study population in this study was patients with CKD and only $50 \%$ were required to have renal replacement therapy and only $19 \%$ of the total study population were treated with hemodialysis. Arteriovenous shunt dermatitis may be seen in $8 \%$ of patients on long-term hemodialysis. But it was not found in this study, rather 4 patients had dermatitis at different parts of the body but whether it was attributable to CKD was not ascertained. Metastatic calcification of the skin in CKD results from secondary or tertiary hyperparathyroidism. Nephrogenic fibrosing dermopathy (NFD), a recently described disorder of unknown etiology, resembles scleromyxedema in some aspects ${ }^{19}$. However these findings were not seen in this study as study population was under hemodialysis for a short period only and none had received renal transplantation.

\section{Conclusion:}

Bangladesh is one of the most densely populated areas in the world. Some of the cutaneous manifestation noticed during study been very refractory to treatment given as a part of management of CKD and have great impact on quality of life of these patients. It was also noticed that some cutaneous manifestation were completely overlooked which might required only simple treatment and great relief could be offered to the patient if a dermatological consultation was sought.

\section{References :}

1. Ackerman B, Chongchitnant SJ, Gou Y, Bennin B, Reichel M, Randall MB. Histologic Diagnosis of Inflammatory Skin Diseases. 2nd ed. Baltimore: Williams \& Wilkins; 1997. p.12-34.

2. Weedon D, Strutton G. Skin Pathology. New York: Churchill Livingstone; 1997.p.135-43.

3. Garg A, Levin NA, Bernhard JD. Structures of skin lesions and fundamentals of clinical diagnosis. In: Gilchrest BA, Paller AS, Wolff K, Leffell DJ, Goldsmith LA, Katz SI, editors. Fitzpatrick's Dermatology in general medicine.7th ed. New York: Mc GrawHill; 2008. p. 25-26.

4. Goldsmith LA. Physiology, Biochemistry, and Molecular Biology of the Skin. Oxford University Press: New York; 1991.p. 67-68.

5. National Kidney Foundation, Kidney Disease Outcomes Quality Initiative (K/DOQI), Clinical guidelines for chronic kidney disease, Evaluation, Classification and Stratification. AM J Kidney diseases. 2002;39 Suppl 2: S170-171.

6. Claudio P, Angelo VM, Ruggero C. Oxford Textbook of Clinical Nephrology. 3rd ed. Oxford: Oxford University Press; 2005.p.1987-89.

7. Morton CA, Lafferty M, Hau C, Henderson I, Jones M, Lowe JG. Pruritus and skin hydration during dialysis. Nephron Dial Transplant. 1996;11:2031-6.

8. Tawade N, Gokhale BB. Dermatologic manifestation of chronic renal failure. Indian J Dermatol Venereol Leprol. 1996;62:155-6.

9. Siddappa K, Nair BK, Ravindra K, Siddesh ER. Skin in systemic disease. In: Valia RG, Valia AR, editors. IADVL Textbook and atlas of dermatology. 2nd ed. Mumbai: Bhalani Publishing House; 2000. p. 938-84.

10.Pico MR, Lugo-Somolinos A. Cutaneous alterations in patients with chronic renal failure. Int J Dermatol. 1992;31:860-3.

11.Weisman K. Graham RM. Systemic disease and the skin. In: Champion RH, Burton JL, Burns DA. Breathnach SM, editors. Rook/ Wilkinson/ Ebling Textbook of dermatology. 6th ed. Oxford: Blackwell Science; 1998. p. 2703-58.

12. Ponticelli C, Bencini PL. The skin in uremia. In: Massry SG, Glassock RJ, editors. Massry's and Glassock's Textbook of Nephrology. 2nd ed. Baltimore: Williams and Wilkins; 1989. p. 1422-6.

13. Guptha AK, Guptha MA, Cardella CJ, Haberman HF. Cutaneous associations of chronic renal failure and dialysis. Int J Dermatol. 1986;25:498-504. 
14. Bencini PL, Montagnino G, Citterio A, Graziani G, Crosti C, Ponticelli C. Cutaneous abnormalities in uremic patients. Nephron. 1985;40:316-21.

15. Etter L, Myers SA. Pruritus in systemic disease: Mechanisms and management. Dermatol Clin. 2002;20:459-72.

16. Kint A, Bussels L, Fernandes M, Ringoir S. Skin and nail disorders in relation to chronic renal failure. Acta Derm Venereol. 1974;54:137-40.

17. Heilman ER, Friedman RJ. Degenerative diseases and perforating disorders. In: Elder D, Elenitsas R, Jaworsky C, Johnson Jr. B, editors. Lever's histopathology of the skin. 8th ed. Philadelphia:Lippincott-Raven; 1997. p. 341-51.

18. Lindsay RM, Briggs JD, Luke RG, Boyle IT, Kennedy AC. Gynecomastia in chronic renal failure. Br Med J. 1967;4:779-80.

19. Udayakumar P, Balasubramanian S, Ramalingam KS, Lakshmi C, Srinivas CR, Mathew AC. Cutaneous manifestations in patients with chronic renal failure on hemodialysis. Indian J Dermatol Venereol Leprol. 2006;72:119-25. 